\title{
Desenvolvimento sustentável no planejamento urbano: uma análise do Plano de Estruturação Urbana das Vargens ${ }^{1}$
}

\section{Sustainable development in urban planning: an analysis of the Vargens' Plan of Urban Structuring}

\author{
Esteves Neto, Fernando Perez; Corrêa, Roberto Machado² \\ ' Programa de Engenharia Urbana da Escola Politécnica da Universidade \\ Federal do Rio de Janeiro (PEU/POLI/UFRJ), Rua Bertrand Russel 385 - \\ Jacarepaguá - Rio de Janeiro, Brasil, perezesteves@gmail.com \\ 2 PEU/POLI/UFRJ, roberto@poli.ufrj.br
}

\begin{abstract}
RESUMO
A dinâmica de desenvolvimento de uma cidade muitas vezes se desvia de uma diretriz inicial. Em situações em que a cidade cresce sem nenhum planejamento, é comum a ocorrência de eventos que causam prejuízos diretos à população. O objetivo geral deste trabalho é exibir uma proposta de modificação no espaço urbano, através do conceito de desenvolvimento sustentável recomendado pelos estudos do UN-Habitat, aplicado ao Plano de Estruturação Urbana das Vargens, Rio de Janeiro, mostrando como é possível desenvolver uma melhor legislação de gestão territorial ao usar os conceitos de desenho urbano conjuntamente com seus parâmetros. Este trabalho se originou à partir de estudos feitos para dissertação de mestrado, onde apresentou-se durante o texto resultados parciais, os quais são possíveis aprofundamento com uma futura abordagem sobre o objeto. O corolário do artigo, mostra a importância de se considerar o desenvolvimento sustentável como arcabouço para o planejamento, mitigando os problemas advindos de parâmetros urbanos mal projetados, o qual dificultam a aprovação legislativa, tornando o poder público ausente na região. Por isso, este trabalho pode contribuir para soluções de problemas de morfologia urbana, principalmente ao abordar como a densidade afeta o planejamento territorial.
\end{abstract}

Palavras-chave: Planejamento, Legislação, Desenho Urbano.

\begin{abstract}
The dynamics of a city's development often deviate from an initial guideline. In situations where the city grows without any planning, it is common the occurrence of events that cause direct losses to the population. The general objective of this paper is to present a proposal for a modification in the urban space, through the concept of sustainable development recommended by the studies of UN-Habitat, applied to the Plan of Urban Structuring of Vargens, Rio de Janeiro, showing how it is possible to develop a better territorial management legislation by using the concepts of urban design with its parameters. This paper originated from studies from master's thesis, where partial results were presented during the text, which are

\footnotetext{
${ }^{1}$ ESTEVES NETO, Fernando Perez; CORREA, Roberto Machado. Desenvolvimento sustentável no planejamento urbano: uma análise do Plano de Estruturação Urbana das Vargens. In: II SIMPÓSIO NACIONAL DE GESTÃO E ENGENHARIA URBANA: SINGEURB, 2019, São Paulo. Anais... Porto Alegre: ANTAC, 2019.
} 
possible to deepen with a future approach on the subject. The corollary of the article shows the importance of considering sustainable development as a framework for planning, mitigating the problems arising from poorly designed urban parameters, which hinders legislative approval, making public authority absent in the region. Therefore, this work can contribute to the solutions of problems of urban morphology, especially when addressing how the density affects the territorial planning.

Keywords: Planning, Legislation, Urban Design.

\section{INTRODUÇÃO}

Uma cidade pode possuir milhões de pessoas e, dentro do seu espaço físico, abranger inúmeras diferenças e peculiaridades geográficas. O Rio de Janeiro é um perfeito exemplo de como uma cidade pode ter inúmeras variáveis que influenciam no aspecto urbano. Os tipos de solos, acidentes geográficos, hidrografia e proximidade com o mar são algumas delas, e tudo isso também influencia no seu aspecto econômico, social e cultural.

Toda essa variedade gera uma diferença no tipo de ocupação urbana e na atenção que os governantes despendem para cada região. Com isso, algumas localidades foram se urbanizando sem um devido ordenamento nem regularização, adensando-se sem acompanhamento da infraestrutura.

Na tentativa de minimizar os danos causados pelo crescimento desordenado, são aprovadas leis que servem de paliativo para a falha ou ausência de um plano urbano integrado. Tais leis tem como objetivo atender as solicitações para resolução de um problema já existente, mas não a prevenção do seu acontecimento.

Este artigo discute questões relacionadas ao conceito de planejamento através do desenvolvimento sustentável. Em particular, trata do desenho urbano e seus parâmetros, que devem ser adotados para alcançar a sustentabilidade projetada, na qual debate-se com a sociedade e seus representantes para alcançar o melhor resultado possível em forma de legislação.

\section{PLANEJAMENTO URBANO}

O planejamento urbano é um dos instrumentos responsáveis pela organização espacial das cidades. Para ser bem-sucedido em sua proposta, o plano deve ser considerado com um processo, composto por um conjunto de interações técnicas, econômicas e sociais, levando em consideração todas as peculiaridades de cada cidade ou região que almeja sua implementação. Assim, dentre as ferramentas do planejamento urbano, pode-se citar o exemplo do plano diretor, procedimento valorizado na política urbana nacional a partir da Constituição Federal de 1988, que versa em seu Título VII, Capítulo II Art. 182.

A política de desenvolvimento urbano, executada pelo poder público municipal, conforme diretrizes gerais fixadas em lei, tem por objetivo ordenar o pleno desenvolvimento das funções sociais da cidade e garantir o bemestar de seus habitantes.

$\S 1^{\circ} \mathrm{O}$ plano diretor, aprovado pela Câmara Municipal, obrigatório para cidades com mais de vinte mil habitantes, é o instrumento básico da política de desenvolvimento e de expansão urbana. (CONSTITUIÇÃO, 1988)

Como visto pela literalidade da lei, a constituição federal obriga o governante a apresentar um plano diretor. O último plano diretor da cidade do Rio de Janeiro foi feito em 2011 , sob forma da Lei Complementar n. ${ }^{\circ} 111$ de $1^{\circ}$ de fevereiro de 2011, que em seus artigos 68 e 69, é definida o conteúdo comum a todos os Planos de Estruturação Urbana (PEU) da cidade, onde se deve estabelecer as diretrizes para o desenvolvimento local. Também visa conter o processo de ocupação desordenada em loteamentos irregulares, clandestinos e invasões, garantir meios de participação da população local para atendimento de suas sugestões, propostas e recomendações. 


\section{DESENVOLVIMENTO SUSTENTÁVEL}

Com os desafios de urbanização, como a população em crescimento, expansão urbana, pobreza, desigualdade, polvição, congestionamento, mobilidade urbana e energia, a Organização das Nações Unidas, através do UN-Habitat, apoia países a desenvolverem métodos e sistemas de planejamento para auxiliar essa mudança no paradigma sobre planejamento urbano e densidade, promovendo sua visão nas escalas nacional, regional e municipal, para fazer as cidades mais compactas, melhores integradas e conectadas, tornando-as socialmente inclusivas e resilientes a alterações climáticas. (SALAT, BOURDIC, KAMIYA, et. al.,2017)

A Nova Agenda Urbana se baseia em 175 recomendações, diretrizes, princípios e reconhecimentos, onde o Dr. Joan Clos i Matheu, ex-diretor executivo do UN-Habitat, conseguiu que esses conceitos fossem sintetizados através do triângulo do desenvolvimento urbano de uma forma simples, como pode ser visto na Figura 1 abaixo. (SALAT, BOURDIC, KAMIYA,et.al.,2017)

Figura 1 - Triângulo do desenvolvimento Urbano

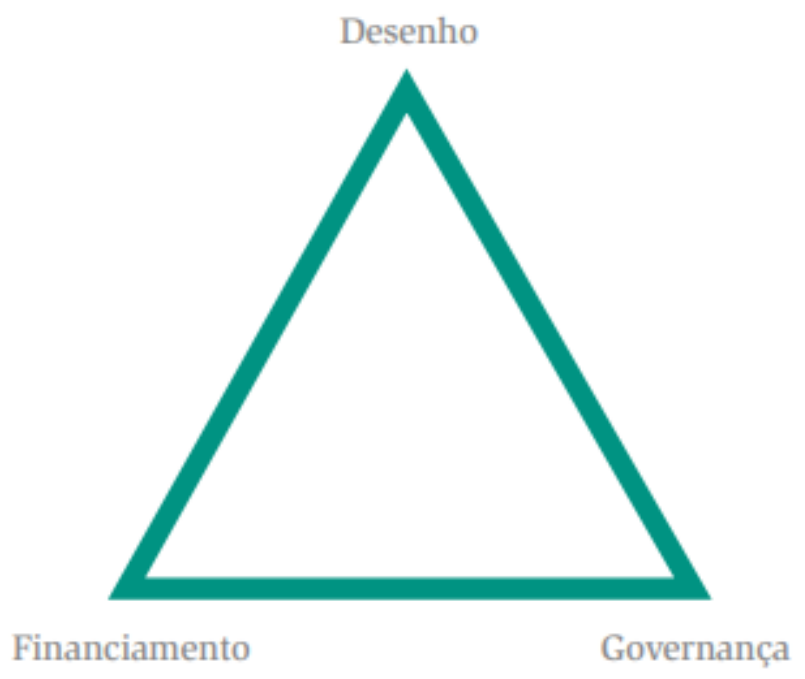

Fonte: SALAT, BOURDIC, KAMIYA,et.al.(2017)

Apesar do planejamento integrado baseado na Estratégia Tripartida do UN-Habitat abordar todos os três vértices do triângulo, somente serão somente abordados os aspectos de desenho para esse artigo.

\subsection{Desenho}

Os aspectos de desenho não devem ser vistos de forma isolada, visto que estão interligados. Cada projeto é parte de um tecido urbano global, de modo que os projetos se interligam entre si e a cidade. Espaço para transporte e pedestres, ciclovias, espaços verdes conectados, são todos parte do que une a cidade. Com mais conexões disponíveis e menores distâncias, os residentes locais podem alcançar escolas, centros comerciais e parques com um menor gasto energético urbano. Quanto maior o número de quarteirões, maior o de interseções, de comércios, de diversidade, de escolha de percursos, de oportunidades para descobertas na malha espacial. Tudo isto resulta em maior vitalidade urbana. A vitalidade das ruas e bairros de uso misto não pode ser alcançada se o tecido urbano subjacente permanecer grosseiro, isto é, vasto e monótono.

No Brasil, um dos instrumentos de desenho urbano mais aplicados, é o zoneamento. Muitas vezes esse zoneamento vem incorporado no próprio Plano Diretor, surgindo como forma de organizar o funcionamento racional das cidades. É de extrema importância a existência de 
leis municipais no que tange ao zoneamento, uso do solo e definição de parâmetros compatíveis com a capacidade de infraestrutura instalada.

Acioly e Davidson (1998) afirmam que a densidade urbana é um dos mais importantes parâmetros de desenho urbano a ser utilizado no processo de planejamento e gestão dos assentamentos humanos. Essa importância dada à densidade, sendo um fator relevante da cidade ideal para a política urbana, infraestrutura e serviço em uma região, torna-se um referencial importante para se avaliar tecnicamente e financeiramente a distribuição e consumo da terra urbana, infraestrutura e serviços públicos nessa área. O autor apresenta uma figura que resumidamente apresenta as vantagens e desvantagens de acordo com mais ou menos adensamento. (Figura 2).

Figura 2 - Vantagens e Desvantagens da Alta e Baixa Densidade

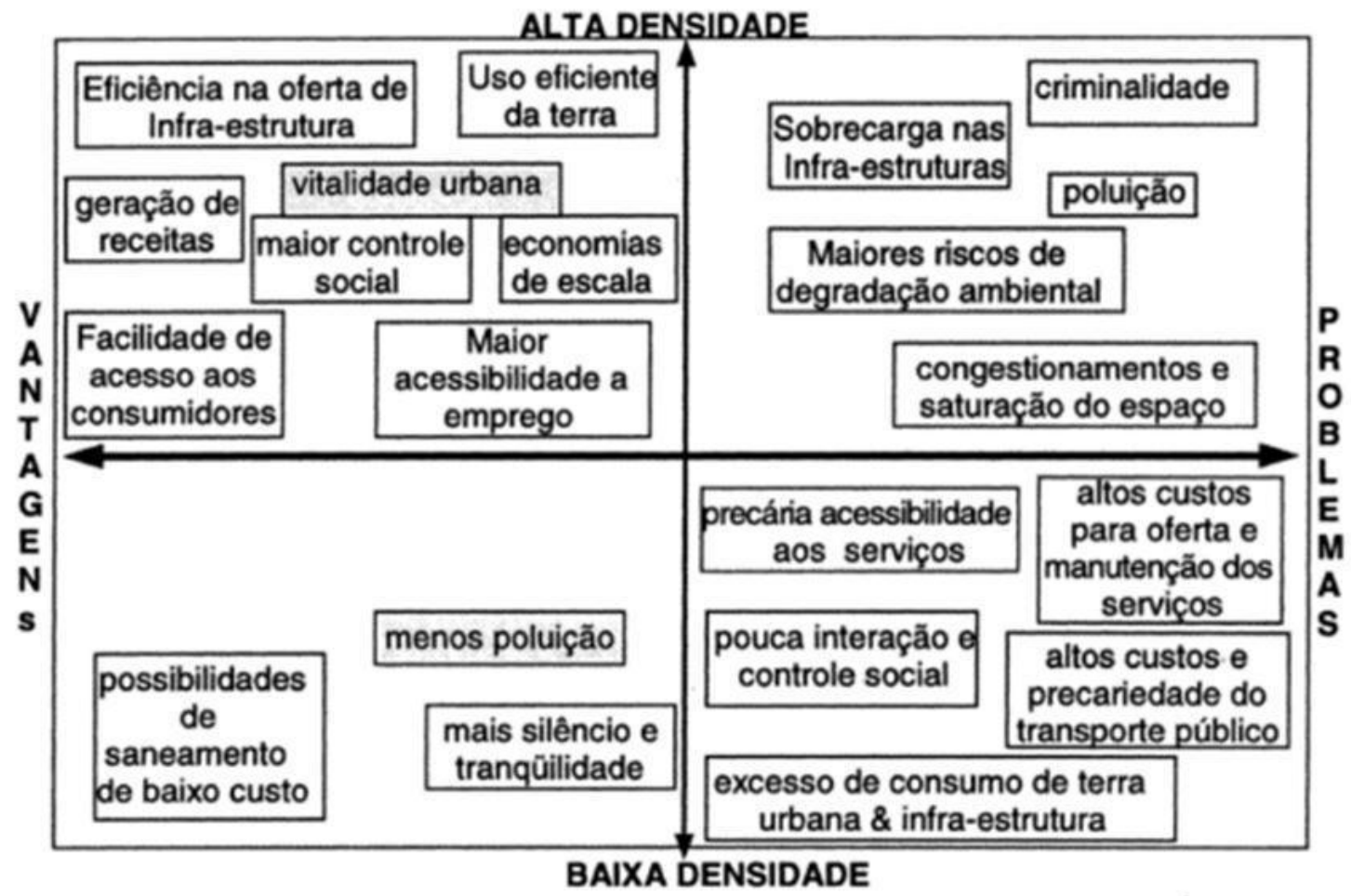

Fonte: ACIOLY e DAVIDSON (1998)

\section{ESTUDO DE CASO - PEU DAS VARGENS}

O estudo de caso foi baseado terreno delimitado pelo Projeto de Estruturação Urbana Lei Complementar (L.C.) 140/2015, que está contido dentro dos bairros de Jacarepaguá, Camorim, Recreio dos Bandeirantes, Barra da Tijuca, Vargem Pequena e Vargem Grande (Figura 3), possuindo uma área de 5.125 ha. Essa região foi escolhida devido ao histórico de dificuldades para aprovação de projetos que visam o seu desenvolvimento planejado. Principalmente pelo fracasso da tentativa anterior de implementação do PEU, através da L.C. 104/209, onde através da mensagem no 137 de 7 de dezembro de 2015, foi admitido pelo poder público, que um dos seus parâmetros urbanísticos estavam demasiadamente elevados, o que causaria uma densificação não condizente com as características da região, com isso, levando a sua suspensão. 
Figura 3 - Fronteira da região delimitada pelo PEU das Vargens nos bairros existentes.

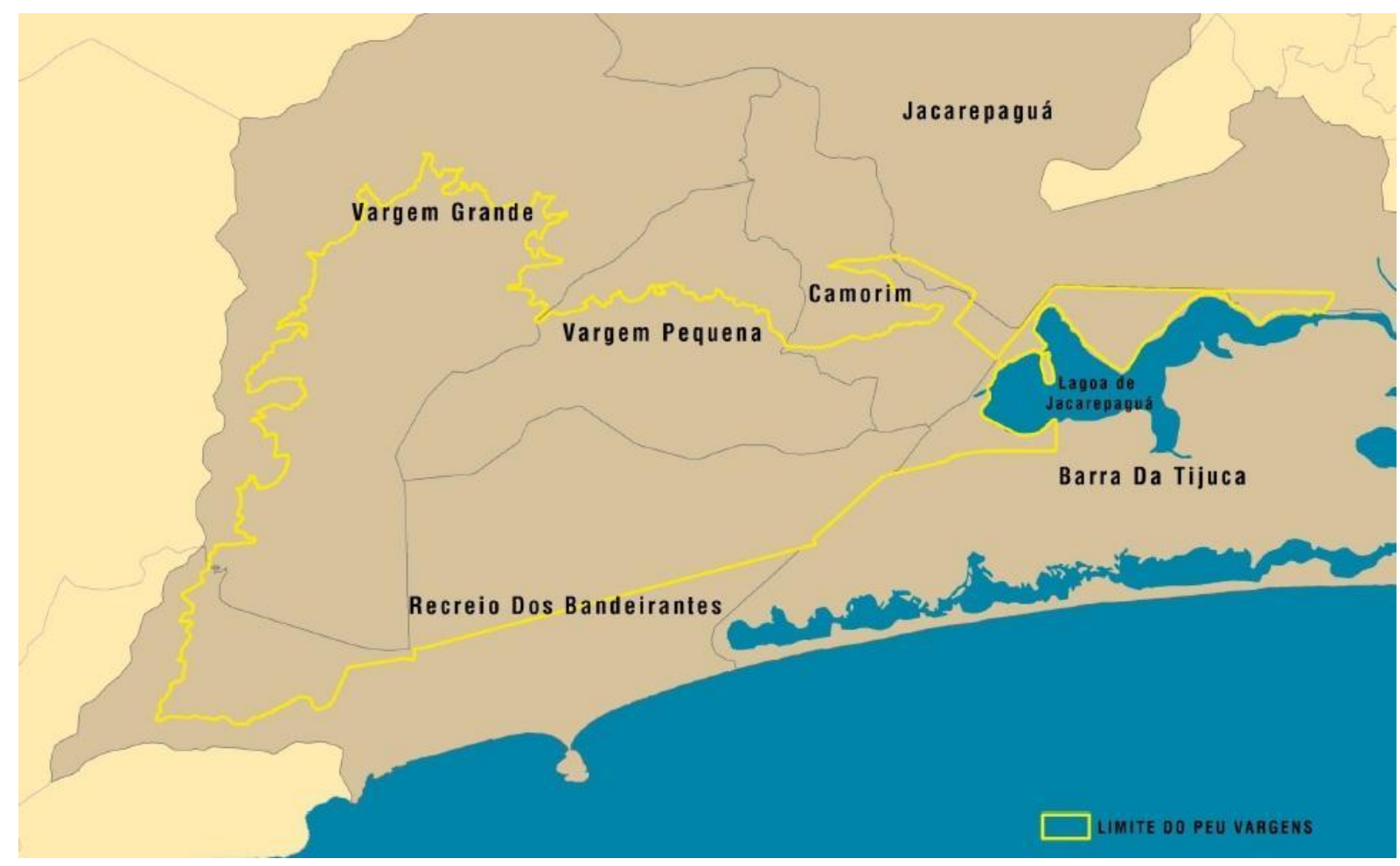

Fonte: SECRETARIA MUNICIPAL DE URBANISMO - SMU (2013)

A área do PEU Vargens está situada na Baixada de Jacarepaguá, cujas regras de ocupação foram originalmente definidas pelo Decreto $n^{\circ} 3.046$ de 24/07/1981 que disciplinou a ocupação do solo na área da Zona Especial 5 (ZE-5).

Atualmente, de acordo com o Plano Diretor de 2011, a região se encontra na Macrozona de Ocupação Condicionada (Figura 4), significando que o adensamento populacional, a intensidade construtiva e a instalação das atividades econômicas serão limitados à capacidade das redes de infraestrutura e subordinados à proteção ambiental e paisagística, podendo ser progressivamente ampliados com o aporte de recursos privados.

Figura 4 - Macrozonas do Rio de Janeiro.

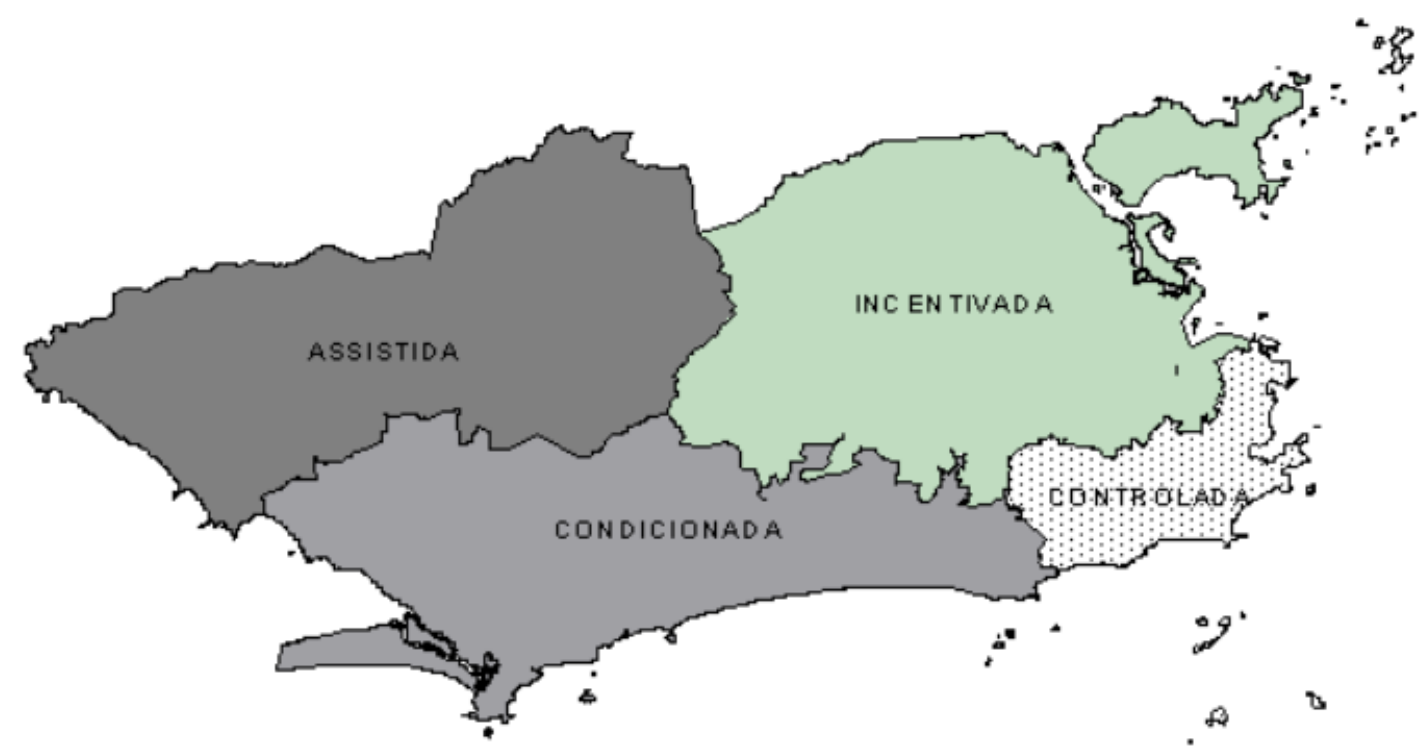

Fonte: RIO DE JANEIRO (2011) 
No Rio de Janeiro, a lei de uso e ocupação do solo apresenta uma padronização das zonas, com suas denominações e conceitos, simplificando sua aplicação às diferentes áreas da cidade pelos Planos de Estruturação Urbana. As zonas podem se caracterizar pela predominância, diversidade ou intensidade dos diversos usos, e se dividem em sete categorias principais: zona de conservação ambiental, agrícola, residencial unifamiliar, residencial multifamiliar, comercial e de serviços, de uso misto e industrial. No PEU das Vargens foram definidas as zonas da região, como pode ver na Figura 5 abaixo.

Figura 5 - Zonas do PEU das Vargens

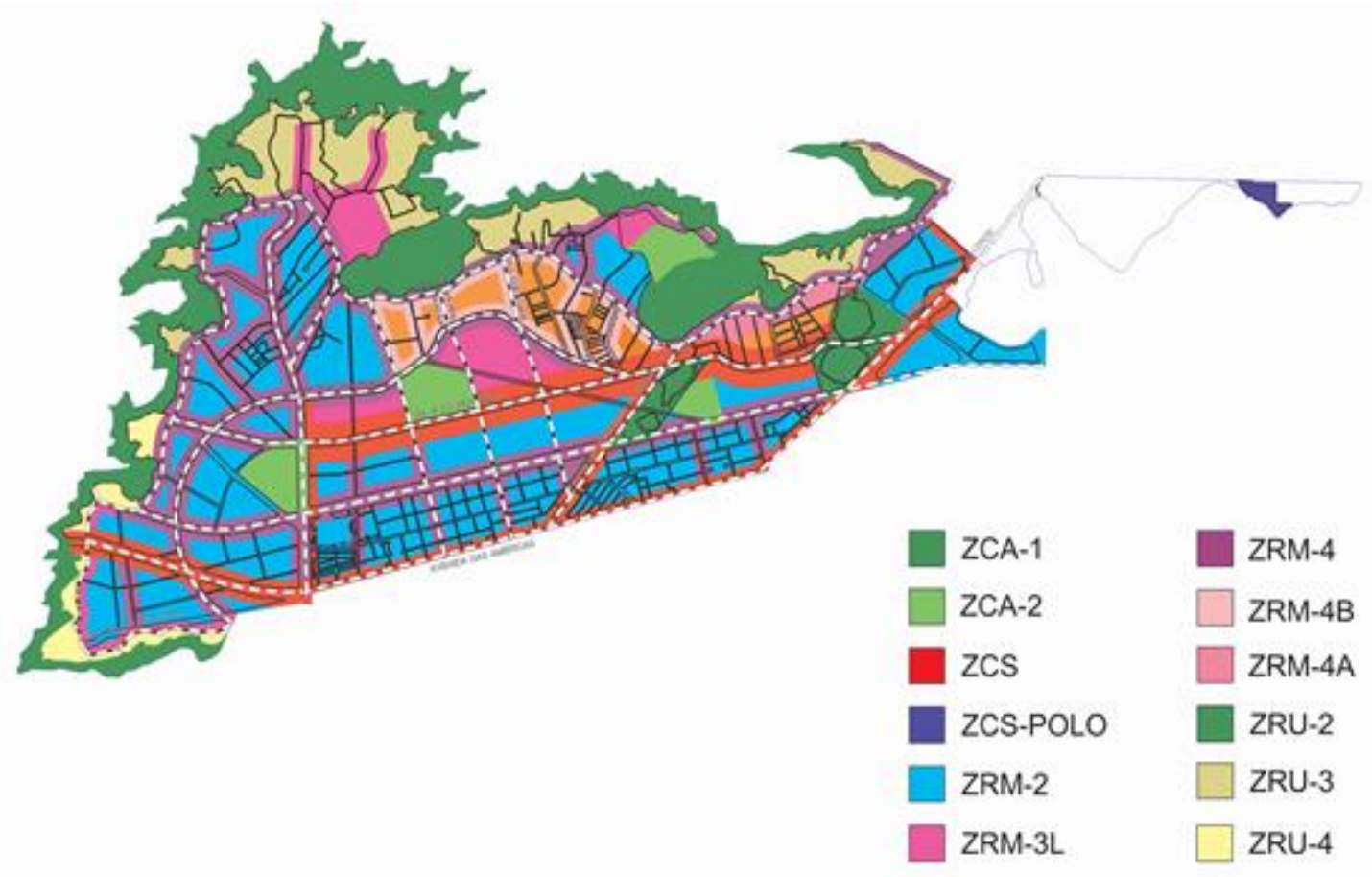

Fonte: Os Autores

Cada zona possui seus parâmetros urbanos específicos, como índice de aproveitamento do terreno, número de pavimentos, taxa de ocupação, dentre outros. Porém, não é estabelecido em nenhum momento densidade máxima. Essa, deve ser prevista de acordo com os indicadores locais. De acordo com a secretaria municipal de urbanismo, a última alteração do PEU, em 2015, a densidade prevista para região era acima de 300 habitantes por hectare (hab/ha), utilizando os parâmetros da L.C..

Para Mascaró (1987), uma densidade que sustente sistemas de infraestruturas com custos otimizados é de aproximadamente 600 hab/ha, entretanto, também é mencionado pelo próprio autor que, densidades próximas de 300 hab/ha já haveria uma perda no sentido de intimidade nos espaços verdes. Já para UN-Habitat, a recomendação é que a densidade deve ser de $150 \mathrm{hab} / \mathrm{ha}$. Como a região delimitada pelo PEU é considerada como Macrozona de Ocupação Condicionada, ou seja, uma região sensível e prioridade na preservação ambiental, pode-se dizer que, para Mascaró, a densidade ideal para essa região seria inferior aos $300 \mathrm{hab} / \mathrm{ha}$.

Já Acioly e Davidson (1998) afirmam que com o patamar de 300 hab/ha não haveriam impactos ao meio natural. Portanto é necessário encontrar o ponto ideal para absorver o custo da implantação da infraestrutura, sem afetar o bem estar da população diretamente envolvida.

Com a posse dessas informações foi possível fazer compilação dos dados, gerando assim uma densidade de acordo com os conceitos apresentados no trabalho e com as características individuais da região de estudo. (Quadro 1). 
Quadro 1 - Densidade por autores e escolhida para região de estudo

\begin{tabular}{|c|r|c|}
\hline Literatura & Densidade (hab/ha) & Obs.: \\
\hline Mascaró & 300 & Densidade Bruta \\
\hline Acioli e Davidson & 300 & Densidade Bruta \\
\hline UN-Habitat & 150 & Densidade Bruta \\
\hline A ser utilizada & $\mathbf{2 5 0}$ & Densidade Bruta \\
\hline
\end{tabular}

Fonte: Os Autores

Ao estabelecer 250 hab/ha como a densidade para região, realiza-se então modificações nos parâmetros urbanos contidos no PEU para adequar-se às boas práticas previstas na literatura. Com isso, é possível deixar a região se desenvolver sem que ocorra uma densificação que prejudique sua característica de ocupação condicionada, facilitando assim a aprovação legislativa que se encontra parada há mais de 10 anos.

\section{CONCLUSÕES}

Ao se pensar em uma legislação que contemple o planejamento urbano, deve-se abordar os aspectos econômicos, de governança e de desenho, de forma integrada. Todos os aspectos devem ser pensados e discutidos para que de forma técnica, possa atender os agentes interessados. Este trabalho propôs através do conceito da estratégia tripartida no desenvolvimento sustentável, demonstrar que os parâmetros urbanos contidos em uma legislação podem tanto ajudar quanto prejudicar uma região. De maneira que, se forem estabelecidos de forma equivocada, acabam por trazer prejuízos ao serem os motivos de não aprovação legal e assim ausentando o poder público de uma localidade.

Houve uma limitação no estudo de caso devido ao tamanho da região. Entretanto, as discussões abordadas no trabalho, a delimitação de uma densidade no local de estudo, poderão orientar futuras pesquisas que visem comprovar a melhoria no ambiente através da alteração dos parâmetros contidos em cada zoneamento.

\section{REFERÊNCIAS}

ACIOLY JUNIOR, Claudio; DAVIDSON, Forbes. Densidade urbana: um instrumento de planejamento e gestão urbana. Rio de Janeiro: Mavad, 1998.

BRASIL. Constituição da República Federativa do Brasil (1988). Promulgada em 05 de outubro de 1988. Disponível em:

<http://www.planalto.gov.br/ccivil_03/Constituicao/Constituicao.htm> Acesso em: 03 set. 2018.

INSTITUTO DE PESQUISA E PLANEJAMENTO URBANO E REGIONAL (IPPUR). Tabela de Área, População e Densidade por Regiōes Administrativas e Macrozonas de Ocupação Urbana do Município do Rio de Janeiro. Rio de Janeiro, RJ, 2009. Disponivel em: <

http://www.camara.rj.gov.br/planodiretor/pd2009/relatoriosIPPUR/relatorio_IPPUR_tabelala. PDF >. Acesso em: 15 fev. 2019

MASCARÓ, Juan Luis. Desenho urbano e custos de urbanização. Brasília: Mhu-Sam, 1987.

ORGANIZAÇÃO DAS NAÇÕES UNIDAS (ONU) (2016). Habitat III: nova agenda urbana. Disponível em: < http://conam.org.br/wp-content/uploads/2017/08/Habitat-Ill_NovaAgenda-Urbana_PT.pdf. > Acesso em: 03 fev. 2019.

A new strategy of sustainable neighbourhood planning: five principles, UNHabitat, Discussion note 3, mai. 2014. 
RIO DE JANEIRO (cidade). Projeto de Lei Complementar 140 (2015). Disponível em:

<http://mail.camara.rj.gov.br/APL/Legislativos/scpro1720.nsf/0/832580830061 F31883257F1500 53FD3E? OpenDocument> Acesso em: 03 set. 2018.

RIO DE JANEIRO (cidade). Projeto de Lei Complementar 111 (2011). Disponível em: <http://www.rio.rj.gov.br/dlstatic/10112/3678296/DLFE-268714.pdf/PlanoDiretor.pdf> Acesso em: 03 set. 2018.

SALAT, S.; BOURDIC, L.; KAMIYA, M.; POR UMA ESTRATÉGIA DE CIDADE SUSTENTÁVEL Expansão Urbana Planeada, Quadro Legal e Financiamento Autárquico. Edições Afrontamento, 2017. Disponível em: <https://nacoesunidas.org/wp-content/uploads/2017/11/cidadesustentavel.pdf> Acesso em: 03 fev. 2019.

SILVA, Geovany Jessé Alexandre da; SILVA, Samira Elias; NOME, Carlos Alejandro. Densidade, dispersão e forma urbana. Dimensões e limites da sustentabilidade habitacional. Arquitextos, São Paulo, ano 16, n. 189.07, Vitruvius, fev. 2016 <http://www.vitruvius.com.br/revistas/read/arquitextos/16.189/5957>. Acesso em: 03 set. 2018.

SMU - SECRETARIA MUNICIPAL DE URBANISMO E MEIO AMBIENTE - PREFEITURA MUNICIPAL DO RIO DE JANEIRO. Relatórios Preliminares à elaboração do Plano Diretor Decenal da Cidade do Rio de Janeiro, Rio de Janeiro, 1990.

Apresentação de debate PEU das Vargens. Rio de Janeiro, 2013. Disponível em: <http://www.rio.rj.gov.br/dlstatic/10112/91237/4160618/PEU_VARGENS_AUDIENCIA.pdf> Acesso em:20 jun. 2018

Lei de Uso e Ocupação do Solo. Rio de Janeiro, 2013. Disponível em: < http://www.rio.rj.gov.br/documents/91237/ddbd40f5-fa89-40ff-b7e3-c2a9339f578d> Acesso em:03 set. 2018. 